\title{
Research on the Financial Management Basic Link Analysis Based on the Circulation Control and Financial Analysis
}

\author{
Lin Cheng \\ Chongqing Vocational Institute of Engineering, Chongqing, China \\ ch_eng_lin@126.com
} Keywords: cycle control; financial analysis; financial management; mathematical model;
optimization

\begin{abstract}
The financial circulation is achieved by having the practical management cycle, its essence is financial analysis, namely the collection of financial analysis table and decision-making various kinds of financial information, to carry out analysis and interpretation. This article embarks on the financial management's circulation control principle and financial analysis method, to deepen financial management basic link, and using the thought of mathematical modeling construct the basic link model of optimal financial management, on the basis of mathematical demonstration, to provide the scientific theory basis and practice path for the field research.
\end{abstract}

\section{Introduction}

From late fifteenth century to early sixteenth century, company financial management origin is until today's high-speed development, financial management system has experienced countless times innovation, financial management theory is also applied in every direction penetration, at home and abroad it is beyond count for the research of financial management [1]. For example, Li Xiaojian's the research of state-owned company financial management mechanism has put forward property right theory by Marx, combined with the modern enterprise theory and modern financial theory, with reference to foreign financial management theory and practical experience, the use of state-owned company financial management mechanism's the basic operation mode and the basic content, to propose the rationalization proposal for existing problems of state-owned company current financial management mechanism, which emphasizes to find the importance of reasonable financial management mechanism [2].

\section{Development of traditional and modern financial management theory}

A. Development analysis of traditional financial management theory

Finance is the products of commodity exchange and production, along with the rapid development of commodity economy, the important of financial management is becoming more and more prominent. Before 20 century, the company finance is considered to be applied science of the microeconomic theory, until the economic crisis of 1929 and the global economy great depression makes financial analysis has further development in the nineteen thirties. Traditional finance theory mainly includes three parts, which are respectively the dividend theory, early investment theory and the random walk hypothesis $[3,4]$. It is specifically shown in Figure 1.

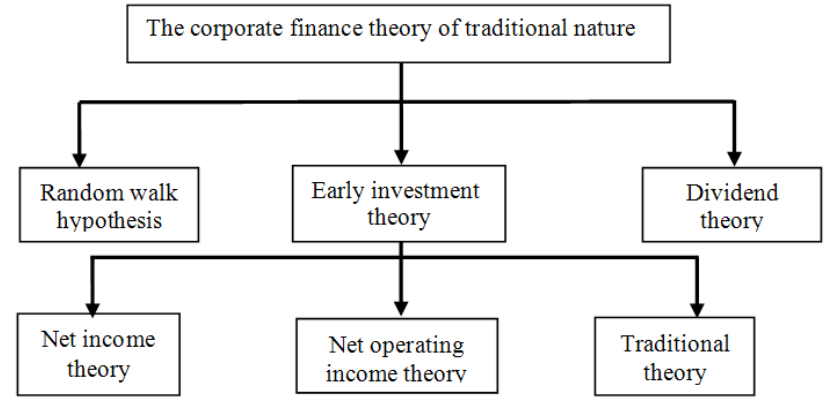

Figure 1. The corporate finance theory of traditional nature 
In Figure 1, the relevance theory is the most enduring theory of dividend, it means that the stock's value is equal to dividend discount values, the formula is:

$$
V_{0}=\sum_{t=1}^{\infty} \frac{D_{t}}{1+K_{t}}
$$

The theory of formula (1) is proposed based on investor's psychological state. Early investment theory includes the three parts of net income theory, net operating income theory and traditional theory, wherein the net income theory argues that the firm can without the fear of debt risk, when the debt proportion reaches $100 \%$, capital agencies benefits will be best; net operating income theory believes that the increase of debt will increase business risk, to deduce the no optimal capital structure of enterprise [5]; the traditional theory emphasizes debt turning point, which is a eclectic theory between net income theory and net operating income theory. The random walk hypothesis was found by French economist Basch Leigh E in the study of national commodity price trend, namely commodity prices and future prices are unable to estimate its value [6].

B. Development analysis of modern financial management theory

From the late 1950s to the late 1970s, financial management content and method are very big change, which is gradually converted from simple financing management and capital management that involves the allocation of a number of economic benefits, income and management. Financial management research center towards the capital budget transfer, a variety of technical analysis methods have been applied to the financial management, enterprises pay more attention to the allocation of the internal funds research $[7,8]$.

With the rise of third science and technology revolution, financial management rapidly towards the direction Yuejin of mathematical modeling analysis, thus has distinct characteristics modern financial management theory that is ceaseless emerge in large numbers [9]. During this period, the main modern financial management theory development process is shown in Table 1.

TABLE I. Financial management theory from the late 1950s to the late 1970s

\begin{tabular}{|c|l|l|}
\hline Time & \multicolumn{1}{|c|}{ Main characters } & \multicolumn{1}{c|}{ Main theory } \\
\hline $\mathbf{1 9 5 2}$ & H.Markowitz & Portfolio theory \\
\hline $\mathbf{1 9 5 8}$ & Miller and Modi Cellay Ni & Capital structure theory \\
\hline $\mathbf{1 9 6 1}$ & Miller and Modi Cellay Ni & Dividend policy theory \\
\hline $\mathbf{1 9 6 5}$ & Sharp, flint and Moss & Capital asset pricing theory \\
\hline $\mathbf{1 9 7 6}$ & Ross & Arbitrage pricing theory \\
\hline $\mathbf{1 9 7 3}$ & Black and Scholes & Complete pricing theory \\
\hline
\end{tabular}

In the 1980s, with the continuous development of the financial, the ceaseless shirt-sleeve among the tool innovation, risk aggravate, product production, product demand and network economy, to make the financial management further deepening, it will appear inspection of the capital asset pricing model validation support, verification and improvement of the arbitrage pricing theory, deepening of capital structure theory, the application of martingale way research methods and so on. At the same time, the new change of economic environment can entry into new basic theory of the financial management, which are mainly expressed as information asymmetric theory and agency theory $[10,11]$.

Entering twenty-first century, interdisciplinary integration as a modern financial management of the new trend of development, the financial management not only stay in the disciplines of simple application, more is interdisciplinary, makes the modern financial management research range is more wide; research subject to realize diversification; research content more rich; research methods science.

\section{Modern financial management cycle control principles and financial analysis techniques}

A. Analysis of modern financial management cycle control principle

Modern financial management is based on the program of financial management, the internal relationship planning between the various parts of financial management have six specific components as shown in Figure 2 [12].

As shown in Figure 2, financial management is decision-making, planning, forecast, control, supervision and analysis that are composed of six steps. In the process of the actual operation, these 
six aspects are the integration of cross operation, each link is closely linked, leading to the formation of the whole process of financial management, the whole financial management will the whole process from the beginning to the end that is called financial management cycle [13].

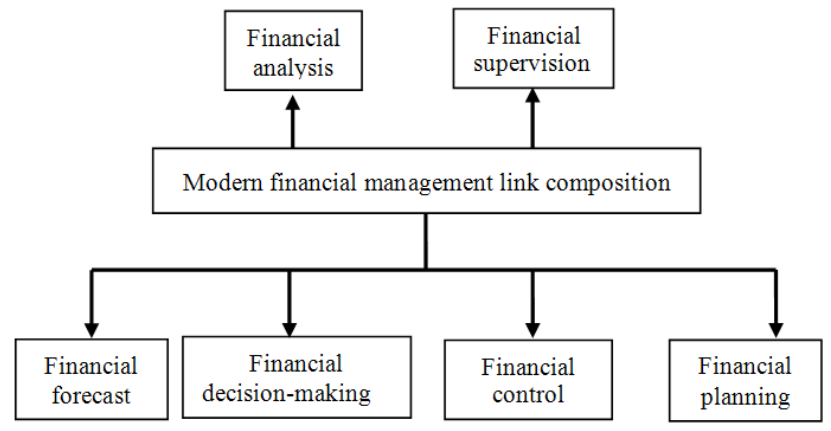

Figure 2. Modern financial management link composition

Financial management cycle includes two aspects that are respectively financial management method (process) cycle and financial management content cycle, its financial management method cyclic has integrated five specialized financial methods by economic management and financial management (forecasting, decision making, analysis, budget, control), which are arranged in sequence and development; the content of financial management cycle mainly involves the allocation of financial funds, mainly including raising management, release management, operation management and distribution management. Financial circulation is achieved by having the practical management cycle effective, which is the essence of financial analysis; financial management cycle loop control principle diagram is shown in Figure 3.

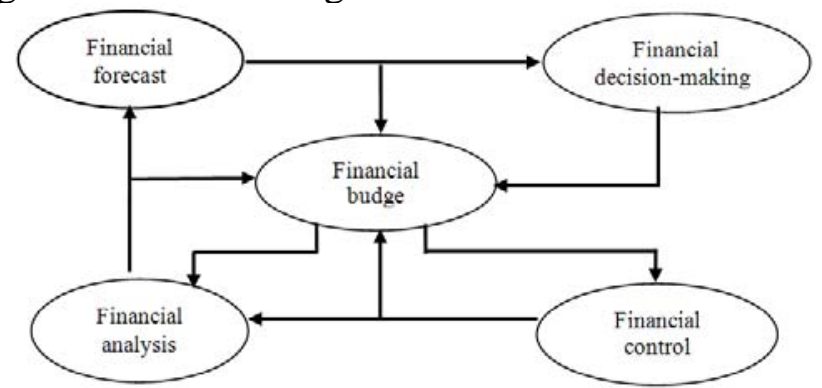

Figure 3. $\quad$ Financial management cycle control principle diagram

In Figure 3, the starting point of financial management cycle control is financial forecast, which is associated with forecast in financial management activities, to provide certain basis for the process of financial management financial decision-making; the correctness of decision is the key link of the whole financial control, which is the strategic choice of financial management cycle; the budget is the core status of the unit in the financial management, it effectively guarantees the financial circulation management in practical operation, which is the action guide of financial management cycle; financial control is relationship lifeline throughout the financial circulation system, through the target partition to form a powerful control system, which is the execution elements of financial management loop; analysis is comprehensive factors index in the process of financial management, comprehensive analysis of internal and external combination is the fundamental guarantee of financial management cycle, it can effectively improve the work efficiency of the whole system, which is the financial management cycle connecting evaluation summary.

B. Modern financial management financial analysis method

On the basis of financial report, modern financial management financial analysis undertake deepening processing, summarizing, comparison research and comprehensive analysis for the report data, at the same time whether the enterprise financial whole and every branch condition is reasonable optimize or not, whether operating results is normal or high status or not etc., to carry out subjective evaluation and objective interpretation. Its main purpose is the overall evaluation of financial condition and results and the overall practice situation of inspection planning and objectives, through the data analysis of mining problems and related reasons of financial operation, to choose a certain reference variable for the scientific decision making, and then to provide academic basis for 
the next step planning and decision-making. The financial analysis of the content mainly consists of three parts as shown in Figure 3.

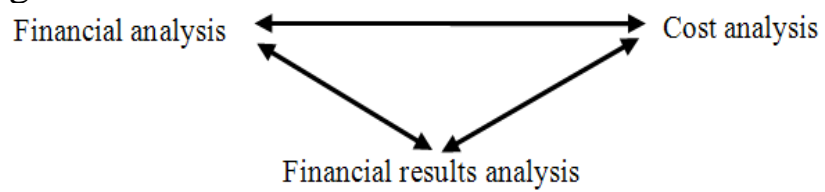

Figure 4. The main content of modern financial management financial analysis

In Figure 4, the main content of modern financial management financial analysis is the analysis among the three of conditions, cost and results, in which the analysis of financial condition relates to the asset allocation, asset, debt and other aspects of the analysis. In the process of financial analysis, it should notice the clear of the whole analysis process, clear data authenticity, analysis of scientific, results clearly, evaluation standard on the significance of the enterprise. Modern financial management financial analysis uses more methods that are three kinds specifically as shown in Table 2.

TABLE II. Modern financial management financial analysis method

\begin{tabular}{|l|l|l|}
\hline Project & Method & Using object and scope \\
\hline \multirow{2}{*}{$\begin{array}{l}\text { Modern financial management } \\
\text { financial analysis method }\end{array}$} & Ratio analysis & $\begin{array}{l}\text { Compared with two relevant indexes, to calculate the mutual ratio and the overall } \\
\text { proportion of various index components }\end{array}$ \\
\cline { 2 - 3 } & $\begin{array}{l}\text { Comparative analysis } \\
\text { method }\end{array}$ & $\begin{array}{l}\text { Compared with two or more than two relevant indexes, analysis between } \\
\text { difference, such as the actual index, index, planning index, history index and } \\
\text { industry index }\end{array}$ \\
\cline { 2 - 3 } & $\begin{array}{l}\text { Comprehensive } \\
\text { analysis method }\end{array}$ & $\begin{array}{l}\text { Related indexes and the impact of the enterprises financial situation's various } \\
\text { factors are orderly in combination with comprehensive analysis }\end{array}$ \\
\hline
\end{tabular}

\section{Analysis of financial management basic link optimization model}

In our country financial management aspects, the study of circulation control principles is still in blank, combined with financial analysis techniques, to perfect the financial management system and deepen the reform of financial management basic link. To the extent practicable, seeking the global optimal solution can expand a financial management analysis of the innovation path. Constructing optimal financial management basic link model, it emphasis on the entire chain risk minimization of financial management, it is expressed as:

$$
\begin{aligned}
& E\left(R_{P}\right)=\sum_{i=1}^{n} W_{i} E\left(R_{i}\right) \\
& \delta_{p}^{2}=W_{i}^{2} \sum_{i=1}^{n} \delta_{p}^{2}+W_{i} W_{j} \sum_{i=1}^{n} \sum_{j=1}^{n} \delta_{i j}(i \neq j)
\end{aligned}
$$

In formula (2) and (3), $E\left(R_{p}\right)$ is expressed as the expected benefit of portfolio; $W_{i}$ is expressed as the securities investment index proportion of $i t h ; \delta_{p}^{2}$ is expressed as the portfolio variance; $\delta_{i j}$ is expressed as relevant securities portfolio covariance. At the same time, those are put forward to achieve maximum efficiency in accordance with the two criteria in the choice of investment combination, the composite curve as shown in Figure 5.

As shown in Figure5, the change of expected income and risk of investors choose presents positive feedback relationship under the value of given expectations. In a certain risk situations, through a combination of investment maximize to make the risk minimization, when financial management basic link, the desired value functions have began to decline. With the increase of $\mathrm{N}$, the stability of expected income depends on the investors' risk selection.

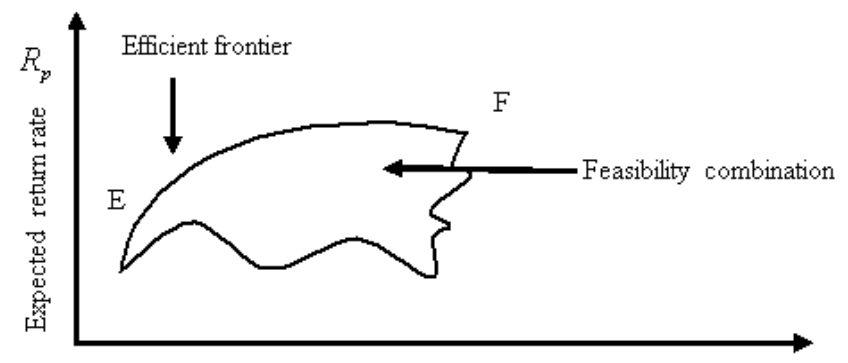

Figure 5.

Ma Vic F's portfolio theory composite curve 
Therefore, as long as $\mathrm{r} \neq 0$ for all industries, no matter how much the value of $\mathrm{N}$, the industry limit given expectation function value is less than 1 . That is no matter how much $\mathrm{N}$, the risk selection of investors is optimization, so the management realized gains do not appear to make the risk maximize.

TABLE III. Stable probability when the expected benefits equilibrium

\begin{tabular}{|l|l|l|}
\hline \multirow{2}{*}{ Never } & $\left(1-\mu^{M}\right) \tau^{A}-\mu^{M}\left(\bar{\tau}^{M}+\rho^{h} \tau^{h}\right)>0$ & $\left(1-\mu^{M}\right) \tau^{A}-\mu^{M}\left(\bar{\tau}^{M}+\rho^{h} \tau^{h}\right)<0$ \\
\cline { 2 - 3 } & $\mu^{\mathrm{M}}\left(\frac{\tau^{A}+\bar{\tau}^{M}}{\tau^{A}+\tau^{h}}\right) \geq \rho^{h}$ & $\mu^{\mathrm{M}}\left(\frac{\tau^{A}+\bar{\tau}^{M}}{\tau^{A}+\tau^{h}}\right)<\rho^{h}$ \\
\cline { 2 - 3 } & Always & For a very small N \\
\hline
\end{tabular}

When expected profit equilibrium, the stable probability is shown in table 3. In the right column, when the $\mathrm{N}$ reaches a certain threshold value, it will satisfy the inequality industry $\mu^{\mathrm{M}}\left(\tau^{A}+\bar{\tau}^{M}\right) /\left(\tau^{A}+\tau^{h}\right)<\rho^{h}$ that exceed expected profit balance, thus breaking the stable equilibrium state of expected profit equilibrium. Assuming that all enterprises have great value in the market risk management function, according to middle column or right column, all sectors are divided into two categories.

\section{Conclusion}

Financial management is the important part of company management system, and prospects 20 years of China's enterprise reform experience, it has created the outstanding achievement that attract people's attention, however there are still many problems to be solved. The application of mathematical modeling method constructs optimal financial management basic model, and carries out mathematical analysis, looking for the close combination of theory and practice, and following the development train of thought from the point starting, point to surface and surface to structure, to construct company financial management mechanism new mode, which can ensure the smooth operation of corporate finance.

\section{References}

[1] Wu Jianglong, Gu Shiying . Study of monetary funds circulation control based on the perspective of financial engineering business process . Network wealth, 2009 (10): 2-12.

[2] Li Xiaojian. Study of state-owned company financial management mechanism . Northwest agriculture and forestry university, 2009: 2-9.

[3] Jin Minghui. Study of enterprise financial management problems based on circular economy . Northeast forestry university, 2009: 34-39.

[4] Zhu Wenli. Research on the enterprise financial management based on the capital movement contradictions and balance . Northwest agriculture and forestry university, 2009 (6): 78-79.

[5] Li Yunliang, Gao Zhaokun. Cconstruction of financial management system based on financial strategy . Accounting research, 2011 (14): 45-46.

[6] Song Yaqin. Study of financial management system based on EVA . Jiangsu business research, 2009 (01): 45-46.

[7] Liu Yang. Enterprise financial management innovation based on Internet era . China trade herald, 2010 ( 08): 89-90.

[8] Geely. Study of enterprise financial information management . Southwestern finance and economics university, 2009: 2-15.

[9] Shen Jun. Research of enterprise financial risk conduction mechanism and control . Wuhan Technology university.2011: 1-9.

[10] Yao Haixin. Financial management . Tsinghua university press, 2009: 89-110.

[11] Robert C.Higgins. Analysis of financial management . Peking university press, 2009: 320-

[12] Wang Lina. Study on the related mechanism of cycle economic externality control . Beijing normal university press, 2011: 110-123.

[13] Liu Feng, Pan Yan, Lin Bin. Fundamental accounting. Higher Education Press, .2009:132146. 